\title{
Open posteromedial dislocation of ankle without associated fractures
}

\author{
Saipramod Yadlapalli' ${ }^{1 *}$, Bezawada Paparao1, \\ Guruvardhan Kumar Venkata Kotha1, Praveen Elaprolu ${ }^{2}$
}

\author{
${ }^{1}$ Department of Orthopaedics, Kamineni Hospitals, Vijayawada, Andhra Pradesh, India \\ ${ }^{2}$ Department of Radiodiagnosis, Sri Lakshmi Narayana Institute of Medical Sciences, Puducherry, India
}

Received: 20 June 2021

Revised: 10 August 2021

Accepted: 11 August 2021

\section{*Correspondence:}

Dr. Saipramod Yadlapalli,

E-mail: yspampramod@gmail.com

Copyright: ( $)$ the author(s), publisher and licensee Medip Academy. This is an open-access article distributed under the terms of the Creative Commons Attribution Non-Commercial License, which permits unrestricted non-commercial use, distribution, and reproduction in any medium, provided the original work is properly cited.

\begin{abstract}
Dislocation of ankle without associated malleoli or talar fractures is a rare presentation. There is no established standard treatment for this condition. Most of them are treated by immediate reduction followed by immobilisation for 6-9 weeks. Majority of them recover without any complications. Here we reported a case of 33 year old man who was injured due to fall from a height, His ankle was deformed with a laceration over lateral side of ankle. Plain radiograph revealed posteromedial tibiotalar dislocation without any associated fractures. Immediate reduction and suturing was performed. At 5 months postoperative review patient was able to perform his daily routine without any instability or complaints.
\end{abstract}

Keywords: Open ankle dislocation, Tibiotalar, Pure dislocation, Ligament repair, Posteromedial

\section{INTRODUCTION}

Though ankle dislocation with fractures is a common entity, pure ankle dislocation without any associated fractures is rare. Ankle joint stability is maintained by ligaments, capsule and ankle mortise. Fahey et al classified ankle dislocations anterior, posterior, medial, lateral, superior or their combinations. ${ }^{1}$ The mechanism of injury consists of forced inversion or eversion of foot in combination with axial loading on a plantar flexed foot. Most of them are open dislocations with laceration of the soft tissues covering the malleoli. ${ }^{2}$ Conwell et al described deformity in relation to its incidence of which posterior dislocation is most common followed by medial, superior and lateral. ${ }^{3}$

Here we reported a case of open posteromedial ankle dislocation without any associated fractures in a 33 year old male patient presented following fall from height. The goal was to discuss appropriate management to achieve good functional outcome as standard treatment protocol was not established.

\section{CASE REPORT}

A 33 year old male weighing $60 \mathrm{kgs}$ presented to emergency room with alleged history of fall from height while doing some electrical works. Patient had electrical burns over his chest and hand. There was a lacerated wound of 8 centimetres over his right ankle on the lateral side with associated with deformity of ankle (Figure 1a). The dorsalis pedis and posterior tibial pulsations were normal. There was no hypoesthesia.

Anteroposterior and lateral radiographic views revealed posteromedial dislocation of tibiotalar joint without any associated fractures malleoli or talus (Figure 1b). Emergency reduction of the joint was performed with patient under sedation. After reduction stability of the joint was ascertained by complete dorsi and plantar flexion of the joint and intraoperative stress testing under image intensifier. Through wash, debridement was done. 

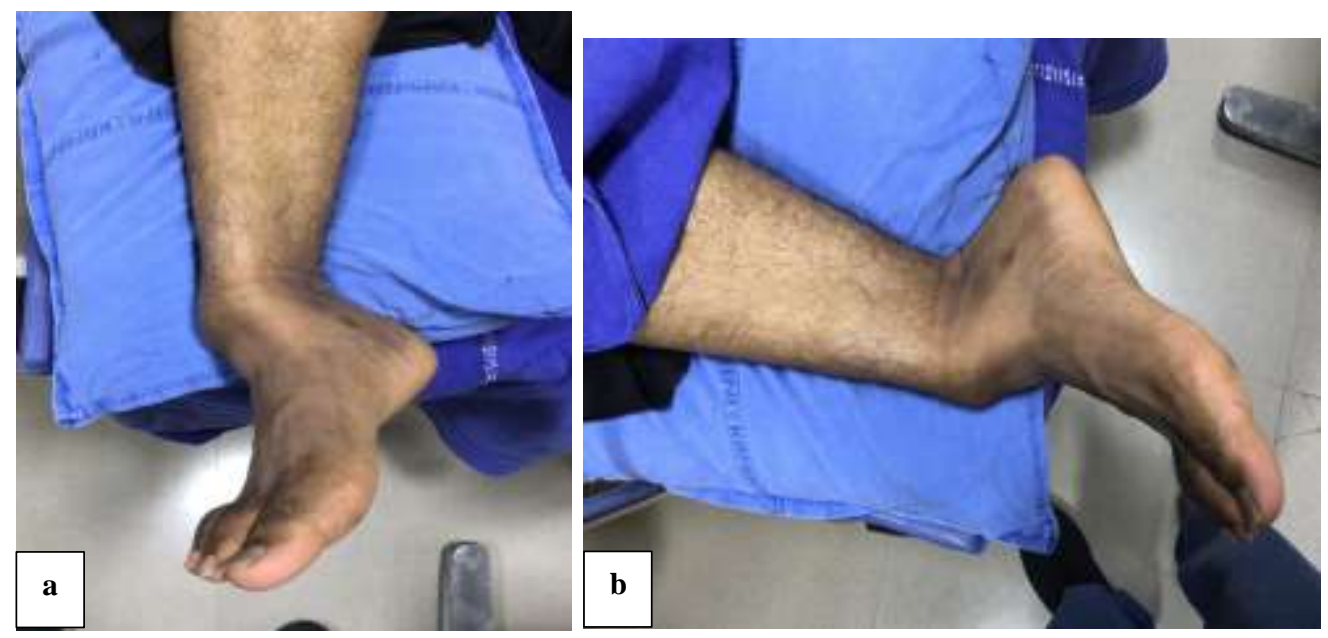

Figure 1: (a) Clinical picture of presentation; (b) pre reduction radiographs.

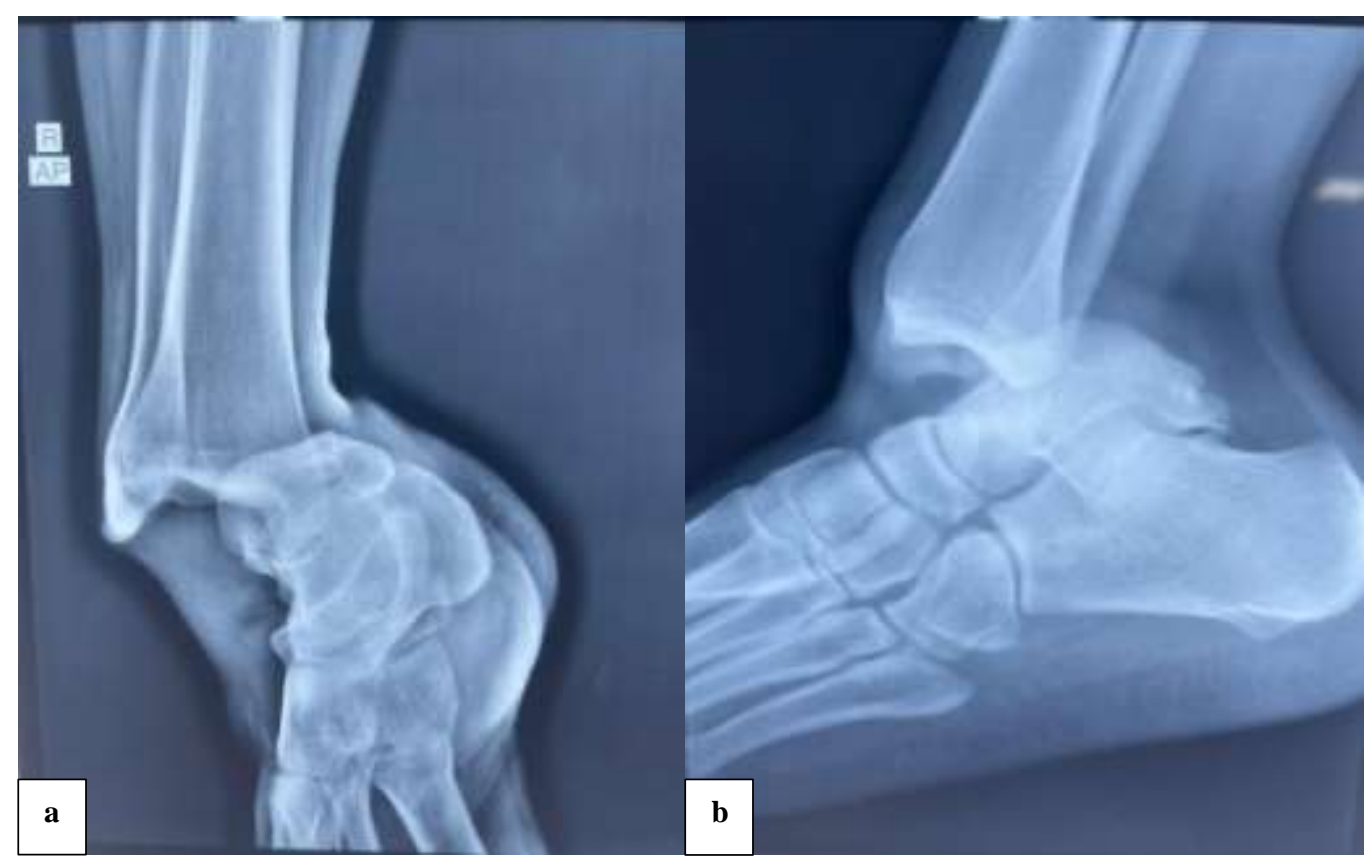

Figure 2: (a and b) Intraoperative pictures showing torn capsule.
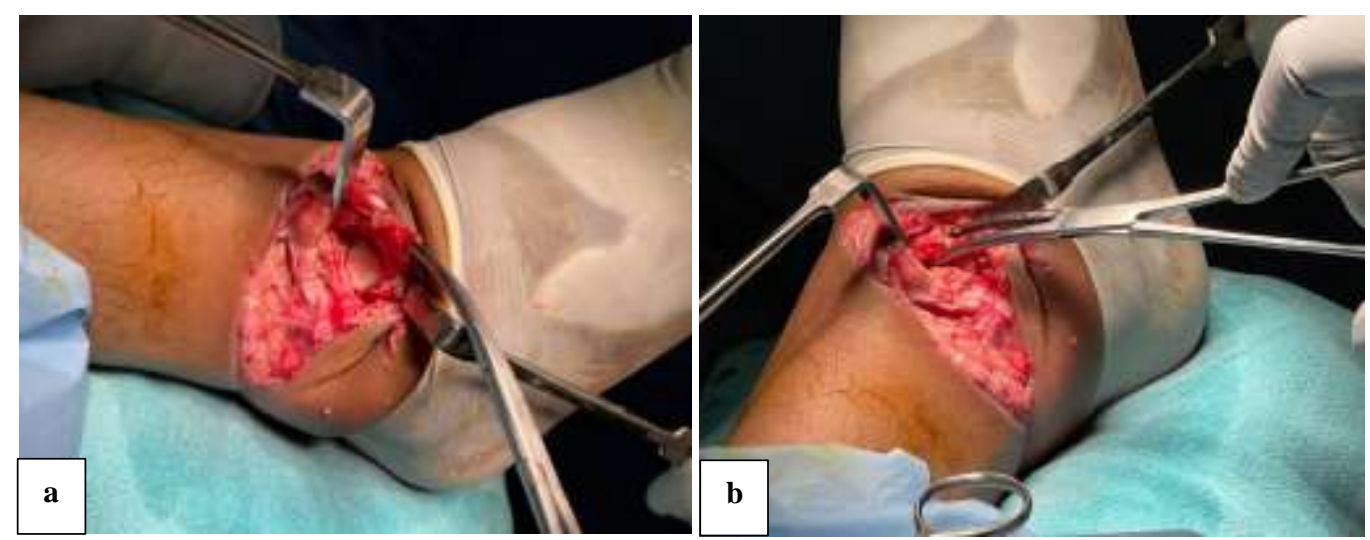

Figure 3: (a and b) Immediate postoperative radiographs. 


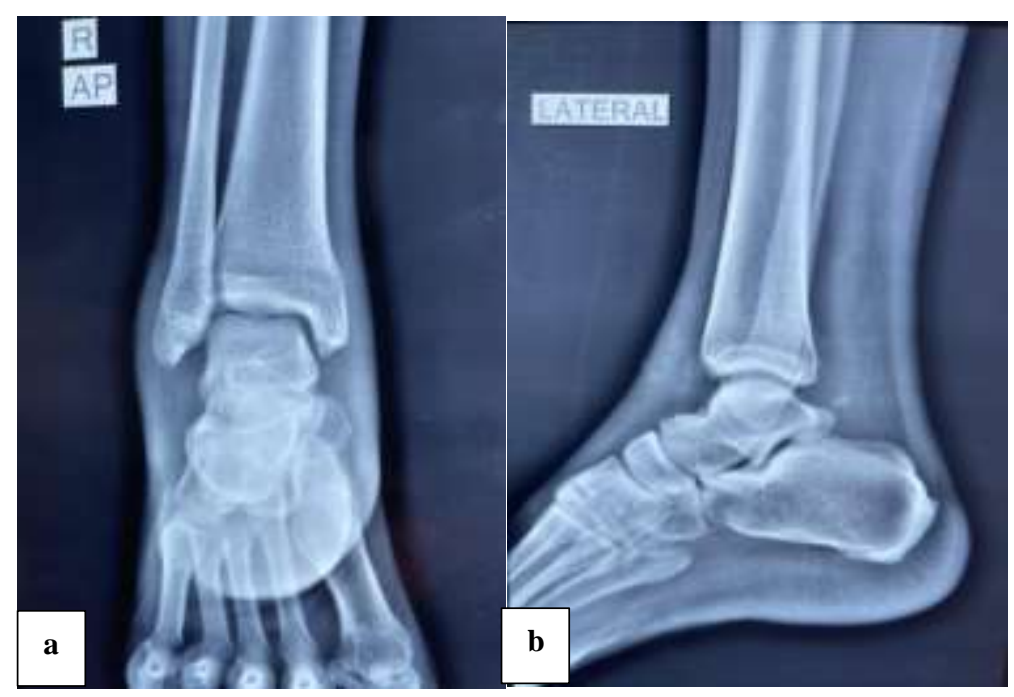

Figure 3: (a and b) Immediate postoperative radiographs.

Exposed capsule was repaired with non-absorbable sutures on the lateral side, stay suturing of the skin was done (Figure 2 and 3). After the procedure ankle was placed in short leg cast in neutral position to be kept for 6 weeks.

After removal of the cast, progressive weight bearing and physical therapy was allowed in following 10 days (Figure 4).

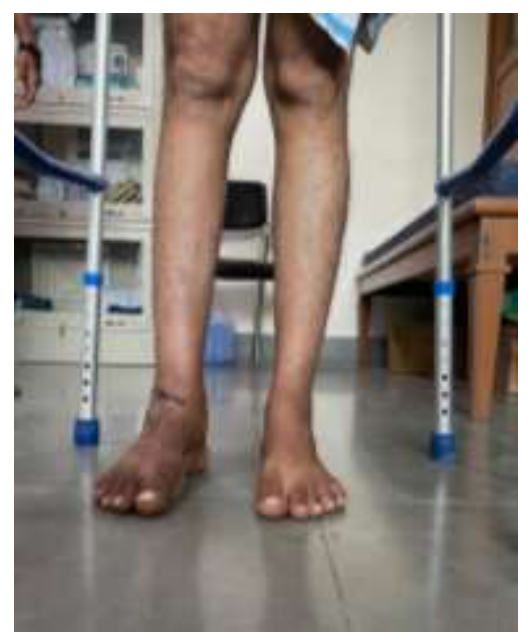

Figure 4: Clinical picture after 6 weeks.

After 6 weeks of postoperative period follow up radiographs were taken to rule out any mal alignment fallowing weight bearing which showed no complexity. Patient had mild swelling of the ankle with no other complaints.

After 5 months following surgery patient was able to attend his daily activity without any complaints with full range of movements and adequate stability.

\section{DISCUSSION}

Ankle dislocation without fracture is a rare entity, ankle discreet stabilization structures laterally and medially like the tibial and fibular malleoli, the collateral ligaments reinforcing the capsule. Ankle dislocation required immense force due to the efficiency of the mortise and the ligaments. ${ }^{4}$ As malleoli were weaker than the ligaments dislocation with the fractures was rare. The unstable position of the ankle was maximal plantar flexion, in this position all the ligaments along with capsule were stretched except posterior talo fibular ligament. With high intensity inversion force resulted in postero medial dislocation of talus on a fixed tibia tearing capsular and ligamentous attatchments. ${ }^{2,3,5,6}$ Some reports also suggested pathological contributions like ligamentous laxity, weak peroneal muscles, repetitive sprains and internal malleolus hypoplasia may result in pure ankle dislocations. ${ }^{7,8}$ Segal et al recommended stress radiographs of the ankle after reduction to rule out subluxations like talo navicular and talocalcaneal joints due to relative ligamentous injury. ${ }^{9}$ Early reduction was key to achieve normal range of movements and lower the risk of complications. ${ }^{10,11}$

At end of reduction the ankle must be immobilized. ${ }^{2}$ Open dislocations allowed exploration and repair of ligamentous structures. According to Colville et al and Gubirio et al it was not necessary to repair collateral ligaments. ${ }^{2,12}$ Patients with open dislocations treated with only repair of capsule had equal results to that of closed dislocations in long-term follow ups .

Kannus et al revied the data regarding open ankle injuries and found no difference between patients with or without ligamentous repair. ${ }^{13}$ 
Most of the complications arose from negative prognostic factors like advanced age, inferior tibiofibular ligament injury, neurovascular injury and delayed reduction according to Elise et al. ${ }^{10}$

In our present case scenario, which was an open postero medial dislocation as the ankle was stable after reduction only capsule and skin repair was done and immobilized in a neutral cast.

Limitations of the study included the sample limited to one patient and the method of treatment which cannot be compared to other modes of treatment.

\section{CONCLUSION}

In conclusion, open postero medial dislocation of ankle without fractures have good long term prognostic outcomes with immediate reduction, standard wound care, assessment of joint stability followed by immobilization. There is no difference between outcome with or without ligamentous repair in a stable reduction.

Funding: No funding sources

Conflict of interest: None declared

Ethical approval: Not required

\section{REFERENCES}

1. Fahey JJ, Murphy JL. Dislocations and fractures of the talus. Surg Clin North Am. 1965;45(1):79-102.

2. Garbuio P, Gérard F, Gagneux E. Pure dislocation of the tibiotalar joint. Report of 9 cases. Rev Chir Orthop. 1995;81:601-8.

3. Conwell HE, Key FC. Management of fractures, dislocations and sprains. 3rd ed. St Louis: CV Mosby; 1942: 1057-64.

4. Uyar M, Tan A, Işler M, Cetinus E. Closed posteromedial dislocation of the tibiotalar joint without fracture in a basketball player. Br J Sports Med. 2004;38(3):342-3.

5. Krishnamurthy S, Schultz RJ. Pure posteromedial dislocation of the ankle joint. Clin Orthop Relat Res. 1985;(201):68-70.

6. Wilson M, Michele A, Jacobson E. Ankle dislocation without fracture. J Bone Joint Surg. 1939;21(1):198-204.

7. Uyar M, Tan A, Isler M, Cetinus E. Closed posteromedial dislocation of the tibiotalar joint without fracture in a basketball player. Br J Sports Med. 2004;38(3):342-3.

8. Tarantino U, Cannata G, Gasbarra E, Bondi L, Celi M, Iundusi R. Open medial dislocation of the ankle without fracture. J Bone Joint Surg $\mathrm{Br}$. 2008;90:1382-4.

9. Segal D, Wasilewski S. Total dislocation of the talus. J Bone Joint Surg Am. 1980;62(8):1370-2.

10. Elisé S, Maynou C, Mestdagh H, Forgeois $\mathrm{P}$, Labourdette P. Tibiotalar dislocations without associated fracture: Report on 16 cases. Acta Orthop Belg. 1998;64(1):25-34.

11. Lazarettos I, Brilakis E, Efsthathopoulas N. Open ankle dislocation without associated malleolar fracture. Case Reps Series. 2013;52(4):508-12.

12. Colville MR, Colville JM, Manoli A. Posteromedial dislocation of the ankle without fracture. J Bone Joint Surg. 1987;69(5):706-11.

13. Kannus P, Renstrom P. Treatment for acute tears of the lateral ligaments of the ankle: operation, cast, or early controlled mobilization. J Bone Joint Surg Am. 1991;73(2):305-12.

Cite this article as: Yadlapalli S, Paparao B, Kotha GKV, Elaprolu P. Open posteromedial dislocation of ankle without associated fractures. Int J Res Orthop 2021;7:1051-4. 